Article

\title{
Socio-Economic Inequalities in Child Stunting Reduction in Sub-Saharan Africa
}

\author{
Kaleab Baye ${ }^{1, * \mathbb{D}}$, Arnaud Laillou ${ }^{2}$ and Stanley Chitweke ${ }^{2}$ \\ 1 Center for Food Science and Nutrition, Addis Ababa University, PO Box: 1176, Addis Ababa, Ethiopia \\ 2 United Nations Children's Fund (UNICEF), Addis Ababa, Ethiopia; alaillou@unicef.org (A.L.); \\ schitekwe@unicef.org (S.C.) \\ * Correspondence: kaleabbaye@gmail.com
}

Received: 18 December 2019; Accepted: 14 January 2020; Published: 18 January 2020

\begin{abstract}
Stunting in children less than five years of age is widespread in Sub-Saharan Africa. We aimed to: (i) evaluate how the prevalence of stunting has changed by socio-economic status and rural/urban residence, and (ii) assess inequalities in children's diet quality and access to maternal and child health care. We used data from nationally representative demographic and health- and multiple indicator cluster-surveys (DHS and MICS) to disaggregate the stunting prevalence by wealth quintile and rural/urban residence. The composite coverage index (CCI) reflecting weighed coverage of eight preventive and curative Reproductive, Maternal, Neonatal, and Child Health (RMNCH) interventions was used as a proxy for access to health care, and Minimum Dietary Diversity Score (MDDS) was used as a proxy for child diet quality. Stunting significantly decreased over the past decade, and reductions were faster for the most disadvantaged groups (rural and poorest wealth quintile), but in only $50 \%$ of the countries studied. Progress in reducing stunting has not been accompanied by improved equity as inequalities in MDDS $(p<0.01)$ and CCI $(p<0.001)$ persist by wealth quintile and rural-urban residence. Aligning food- and health-systems' interventions is needed to accelerate stunting reduction more equitably.
\end{abstract}

Keywords: stunting; inequities; sub-Saharan Africa; continuum of care

\section{Introduction}

Stunting in children less than five years of age is widespread in low and middle income countries (LMIC), with significant proportions of stunted children found in South East Asia and Sub-Saharan Africa [1]. In 2018, $>30 \%$ of children younger than five years of age were stunted in South Asia and Sub-Saharan Africa. This is significantly higher than in WHO regions like Latin America and the Caribbean (9\%) [2]. The causes of stunting can be complex and includes poor maternal health and nutrition, suboptimal infant and young child feeding practices, as well as diseases (e.g., infections); hence, addressing these causes has been given a priority [3]. Stunting has been associated with the compromised growth and development of several organs, including the brain; hence, is linked to poor cognitive and physical performance, which in turn undermines the education, productivity, and future earnings of those affected [4-6]. The economic cost of stunting has been estimated to be as high as $\sim 10 \%$ of the Gross Domestic Product (GDP) of African countries [7].

Recognizing the largely irreversible consequences of stunting, many African countries have joined the first 1000 days movement that aims to prevent malnutrition from conception to the second birthday of the child [8]. The African Regional Nutrition Strategy (ARNS) adopted by member states of the African Union, and in line with the World Health Assembly, has targets to reduce the number of stunted children younger than five years of age by $40 \%$, by 2025 [9]. Consequently, multiple nutrition-specific/-sensitive interventions have been implemented to varying extents. 
Nevertheless, many African countries rely on external support to fund nutrition interventions, and limitations in institutional capacities to effectively implement interventions at scale can also compromise the coverage of key interventions [10]. The extent to which nutrition interventions are reaching those who need them the most remains largely unknown. This is unfortunate, as inequalities in the coverage of essential interventions and thus in stunting reduction, can sustain or even exacerbate long-term inequalities. Therefore, the aim of this study was to evaluate the access of essential health interventions, diet quality, and stunting by wealth quintile and rural/urban residence.

\section{Methods}

\subsection{Data Sources}

The most recent available data were obtained from nationally representative cross-sectional Demographic and Health Surveys (DHS) from Sub-Saharan African countries. The DHS gather data on indicators that can help assess access to health care, child nutrition, and infant and young child feeding practices. For example dietary diversity, meal frequency, and the proportion of children meeting the minimum adequate diet are captured using standardized questionnaires. The DHS uses a multistage stratified sampling design, with households drawn randomly at the last stage.

\subsection{Data Analyses}

\subsubsection{Stunting}

Stunting was defined as height/length-for-age z-scores $<-2$ SD relative to the WHO child growth standards [11]. The prevalence of stunting was estimated for children younger than five years of age. The time trends in stunting by urban-rural residence and wealth quintile was presented for countries with at least two surveys spaced between 1998-2008 and 2009-2018. The annual absolute excess change was presented by deducting the percentage point changes in the urban to the rural, and the prevalence in the wealthiest to the poorest. Negative values indicated faster changes in the most disadvantaged group (poorest wealth quintile/rural).

\subsubsection{Composite Coverage Index}

The Composite Coverage Index (CCI) is a weighted score reflecting the coverage of the following eight preventive and curative Reproductive, Maternal, Neonatal and Child interventions (RMNCH) along the continuum of care-(1) demand for family planning satisfied (modern methods); (2) antenatal care coverage (at least four visits); (3) births attended to by skilled health personnel; (4) BCG immunization coverage among one-year-olds; (5) measles immunization coverage among one-year-olds; (6) DTP3 immunization coverage among one year-olds; (7) children aged less than five years with diarrhea receiving oral rehydration therapy and continued feeding; and (8) children aged less than five years with pneumonia symptoms taken to a health facility $[12,13]$. The interventions, although not directly linked to nutritional outcomes, are good proxies of access to health care, which is the entry point for most nutrition-specific interventions. For example, vaccination coverage can be a proxy for Vitamin A supplementation, 4+ antenatal care for nutrition counseling, and oral rehydration therapy, and continued feeding during diarrhea can be related to counseling on child feeding during and after sickness. The CCI has been successfully used to track the changes in universal health coverage, but also to monitor the within country socio-economic inequalities $[13,14]$. Data used to calculate the CCI are derived from the re-analysis of the Demographic and Health Surveys (DHS), Multiple Indicator Cluster Surveys (MICS), and Reproductive Health Surveys (RHS) data, which are publicly available.

\subsubsection{Infant and Young Child Feeding Practices}

The proportion of infants and young children that are meeting the minimum meal frequency (MMF), minimum dietary diversity (MDD), and minimum acceptable diet (MAD) were calculated 
using the revised UNICEF/WHO indicators [15]. As part of the DHS survey design, these indicators are collected from the youngest child under two years of age born to mothers aged 15-49 years and from children living with the mother at the time of the survey. The revised UNICEF/WHO indicator counts breastfeeding as one group, thus allowing better comparability between breastfed and non-breastfed children.

\subsubsection{Socio-Economic Stratification}

Wealth quintiles and place of residence were used as stratification variables in our analyses. DHS uses a wealth index derived using principal component analyses applied to a list of household assets/characteristics, which are country-specific. The first quintile (Q1) represents the $20 \%$ poorest families, and the last quintile (Q5) represents the $20 \%$ wealthiest families. Quintiles correspond to the relative position of households within each national sample. Urban and rural residence was classified according to boundaries provided by local authorities.

\subsection{Ethics}

All the analyses were based on publicly available data from national DHS surveys. Ethical clearance was the responsibility of the institutions that administered the surveys. The data was obtained after registering in the DHS website, and the datasets did not contain any personal identifiers.

\subsection{Statistical Analyses}

Analyses were done using SPSS version 20. Descriptive statistics were presented as a mean or median for continuous variables, and as a percentage for counts. Inequalities in stunting prevalence and complementary diet quality measures were presented by wealth quintile and rural/urban residence using equiplots (http://www.equidade.org/equiplot.php) generated using STATA version 12. Each horizontal line shows the results by quintile or rural/urban for a given country. Normal distributions of the variables were checked using Kolmogorov-Smirnov test. Independent- $t$-test was used to compare CCI and DDS between rural-urban and poorest-richest wealth quintiles. $p$-values $\leq 0.05$ were considered statistically significant.

\section{Results}

\subsection{Trends in Stunting Prevalence}

Stunting prevalence was significantly reduced in most regions of the world, where the highest burden of stunting is reported (Figure 1). Africa has witnessed an average of 18-percentage point reduction in stunting, since 2000. However, Asia, and Latin America and Caribbean regions noticed a much faster reduction in stunting in the 2000-2016 period.

\subsection{Rate of Stunting Reduction by Rural-Urban Residence and Wealth Quintile}

Figure 2 presents the comparisons in stunting reduction by rural-urban among the 30 countries that had at least two surveys in the period of 1998-2018. Our findings show that a relatively faster change in urban than in rural settings in 10/30 countries. 


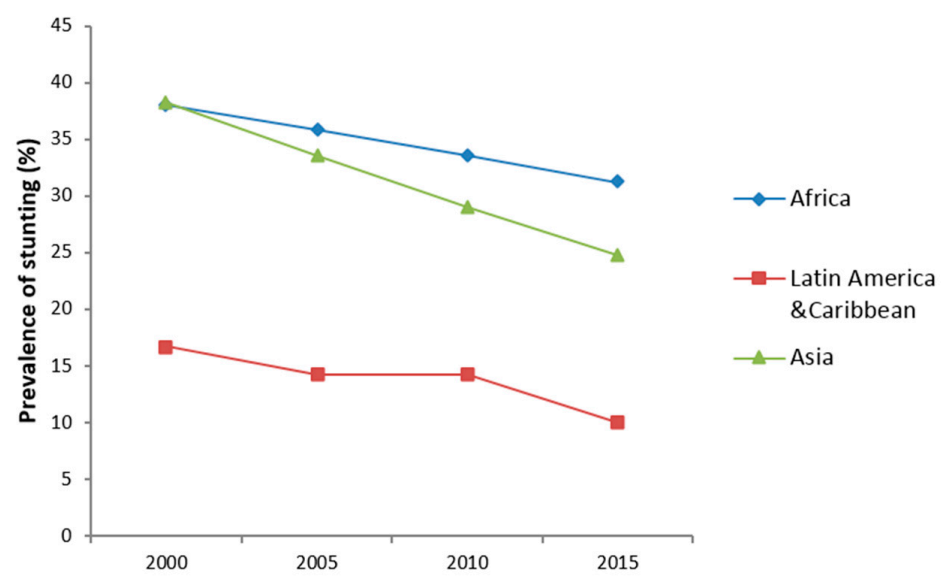

Figure 1. Average stunting reductions in regions with Low- and Middle-Income Countries (LMIC). Authors' graph using UNICEF-WHO-The World Bank: joint malnutrition estimates [2].

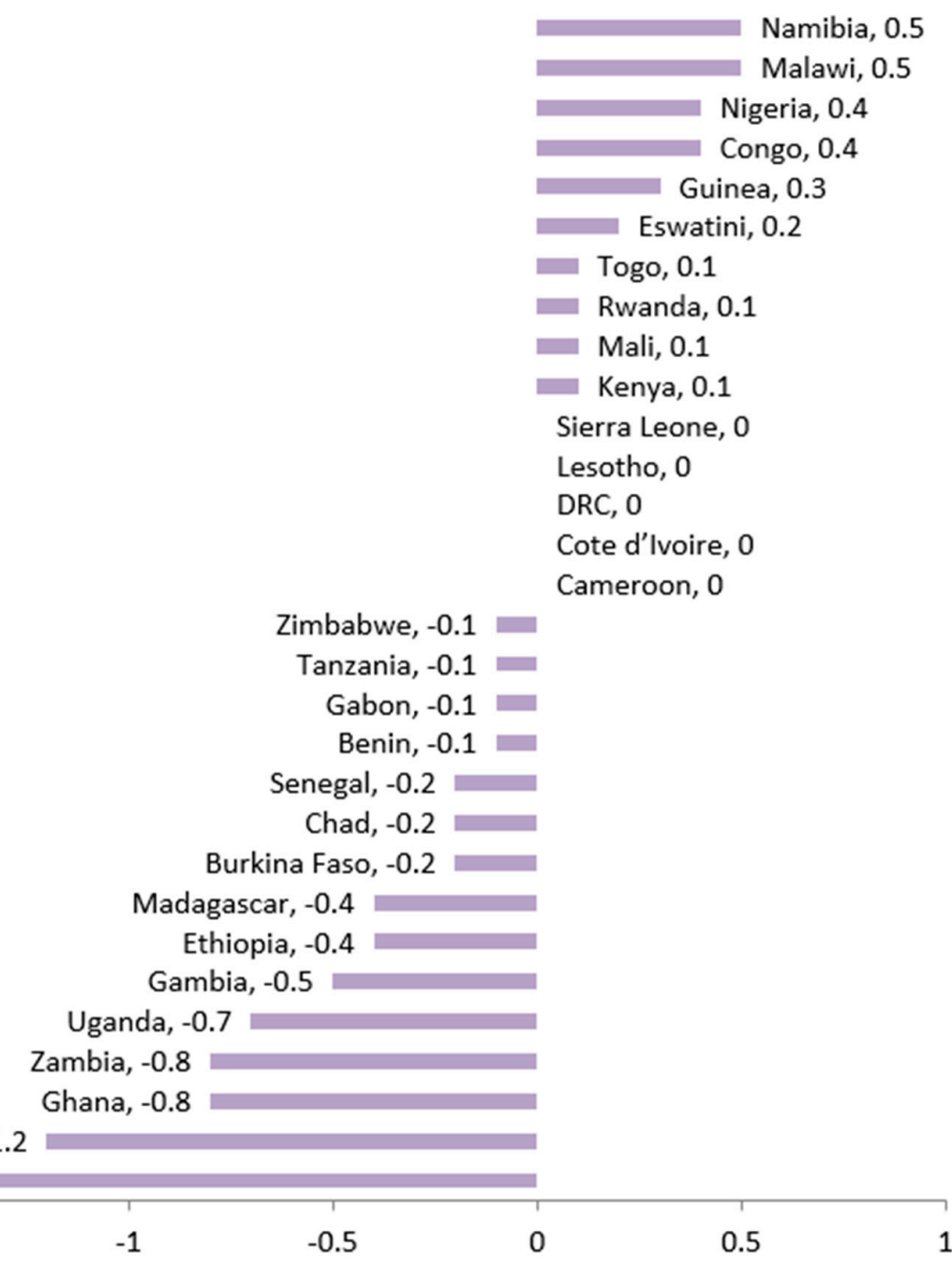

Figure 2. Change of stunting prevalence in rural relative to urban residence (rural-urban) over 1998-2008 to 2009-2018 periods. The graph presents excess changes relative to urban residence; negative values are desirable outcomes as it means faster changes in stunting are happening in the most disadvantaged group.

The same rate of stunting reduction was observed by rural/urban residence in 5/30 of the countries. In 15/30 of the countries, a relatively faster pace of change was observed in rural than in urban settings. 
Figure 3 presents the pace of change in stunting between the poorest and the richest quintiles. An equal number of countries (15/30) had stunting reductions faster in the wealthiest than in the poorest quintile and vice-versa.

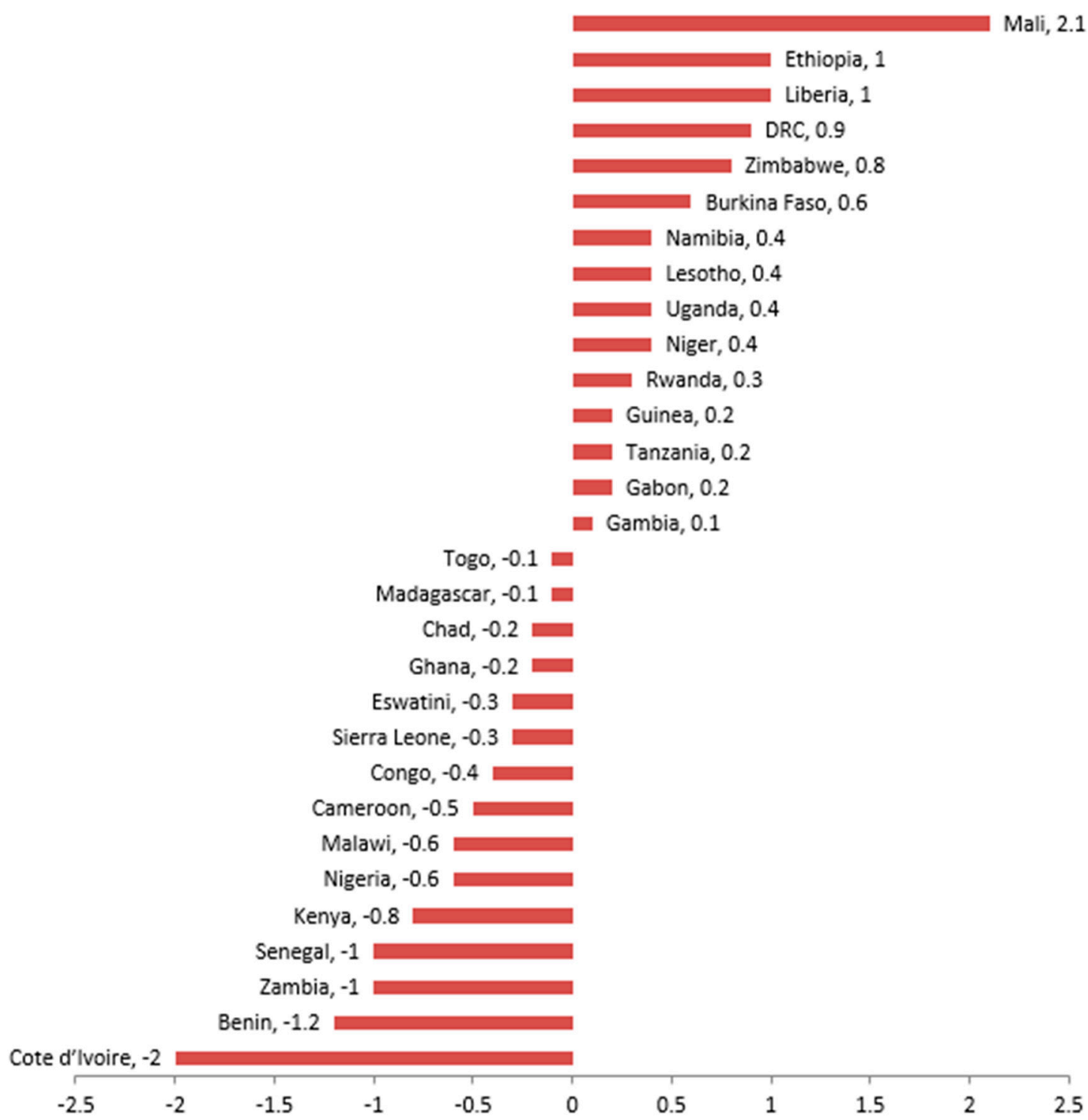

Figure 3. Change of stunting prevalence in the poorest relative to the wealthiest quintile (poorest-richest) over 1998-2008 to 2009-2018 periods. The graph presents excess changes relative to the wealthiest quintile; negative values are desirable outcomes as it means faster changes in stunting has happened in the most disadvantaged group.

\subsection{Most Recent Estimates of Stunting Prevalence by Rural/Urban Residence and Wealth Quintile}

Figure 4 presents the stunting prevalence by rural/urban residence for the most recent DHS survey. In all cases, the stunting prevalence was lower in the urban than in the rural areas. Stunting prevalence in urban settings ranged from $10 \%$ in Senegal to $43 \%$ in Madagascar. Stunting prevalence in rural settings ranged between $20 \%$ in Senegal and 59\% in Burundi. 


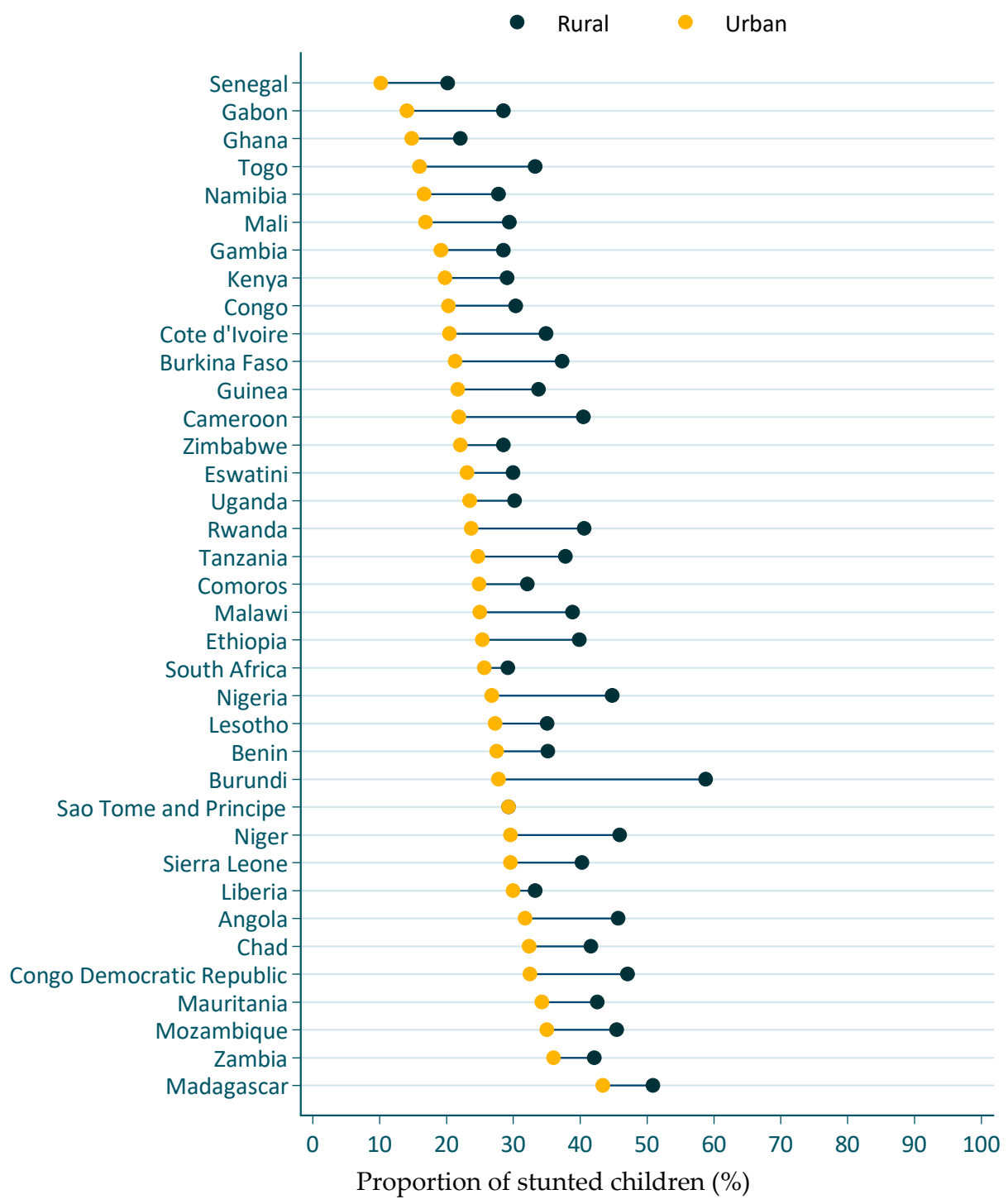

Figure 4. Stunting prevalence by rural/urban residence. Data is from the most recent demographic and health surveys. Dots show stunting prevalence estimates for children younger than five years of age residing in rural (navy blue) and urban (orange) residence.

Similarly, the wealthiest quintile had the lowest prevalence of stunting (Figure 5). Countries like Cameroon, Burundi, and Nigeria had a high spread of stunting prevalence between the poorest and the wealthiest quintile. A difference in stunting prevalence of $35-38 \%$ was observed between the poorest and the wealthiest quintiles. 


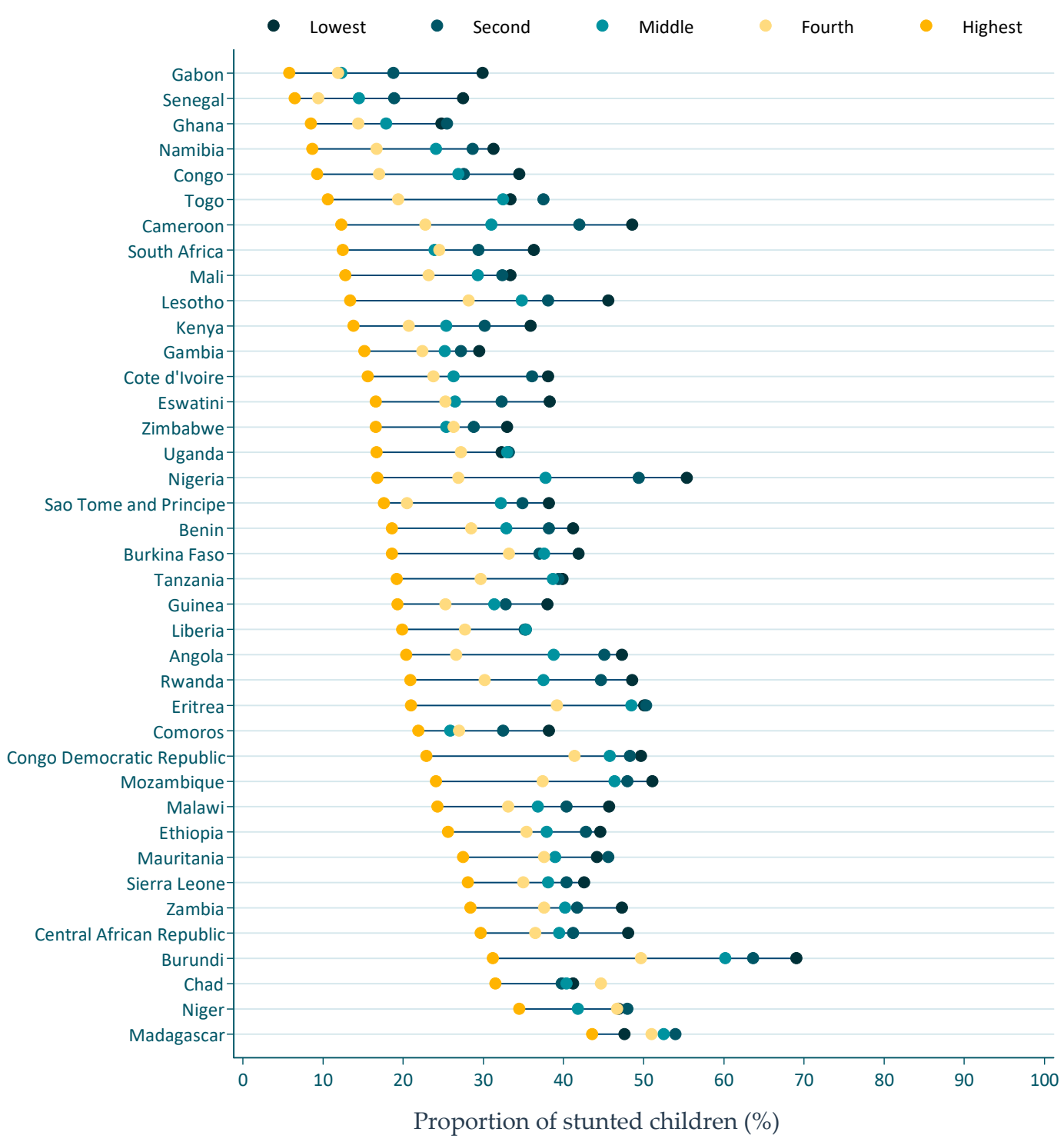

Figure 5. Stunting prevalence by wealth quintile. Dots represent estimated stunting prevalence for the poorest, second, middle, fourth, and the highest wealth quintile.

\subsection{Access to Essential Health Care and Child Feeding Practices (Diet Quality)}

Compared to the urban and the wealthiest quintile, the poorest quintile and the rural had a lower CCI and proportion of children meeting the MDDS $(p<0.01$; Figure 6$)$. Only 2 in 5 children met the MMF, about 1 in 5 met the MDDS, and less than 1 in 10 met the criteria for MAD (Supplementary Materials File S1). 

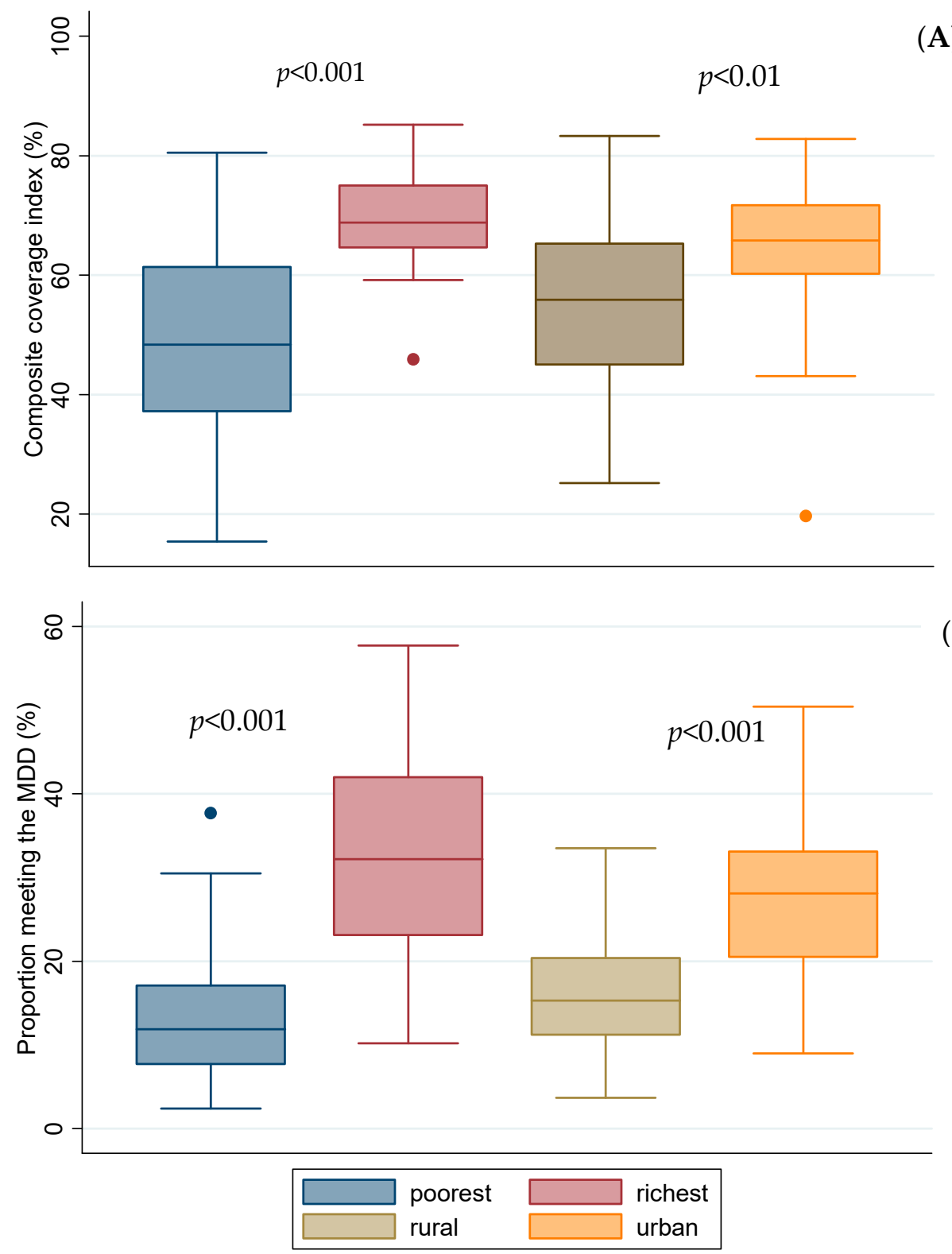

(B)

Figure 6. Coverage index of eight reproductive maternal neonatal and child interventions along the continuum of care (A) and proportion of children meeting minimum dietary diversity score (B) by rural/urban and poorest/richest quintile $(n=34)$. The boxplots present country level analyses of the latest round of DHS or MICS. Statistical tests are from independent $t$-test comparing prevalence in the poorest to the richest quintiles and rural to urban residents.

\section{Discussion}

The present study highlights that the stunting prevalence has declined in most parts of the continent, but the pace of change was not the same everywhere in Africa. In about half of the studied countries, faster rates of change were observed in the most disadvantaged communities (rural and poorest quintile). Despite these changes, the stunting prevalence remains unacceptably high, with significant disparities by wealth quintile and rural-urban residence. These disparities are also illustrated in children's diet quality and access to health care.

One in three or 58.8 million African children younger than five years of age are stunted. This means that a substantial proportion of African children will have compromised physical and cognitive development, which further undermines their health, education, productivity, and future earnings $[4,8]$. 
This is estimated to cost African countries about $~ 10 \%$ of their GDP per capita [7], but this human capital loss may not be equally bared by all segments of the population. Indeed, our stratification of stunting prevalence by rural-urban and wealth quintile illustrates that the poorest quintiles and rural communities are disproportionately affected. Some signs of narrowing inequalities through faster stunting reductions in the most vulnerable groups (poorest quintile and rural residence) were noticed, but in only about half of the studied countries.

Inequalities in stunting prevalence can have multiple reasons and may be symptoms of inequitable resource-sharing and governance, or can be related to harsh environmental conditions, conflicts, etc. $[16,17]$. Indeed, in many LMIC, the poorest segment of the population remains marginalized and suffer from poor infrastructure, low income, gender inequality, and limited access to education and health services, which entraps it into a vicious cycle of poverty and poor health $[18,19]$. The coverage of essential curative and preventive $\mathrm{RMNCH}$ interventions (CCI) confirms this inequality in the access to the most basic health care, which can partly be related to insufficient funding to deliver interventions at scale. This is particularly the case for nutrition interventions, as for example in 2015, high stunting burden countries only invested 1\% (2.9 billion USD) of their annual health budgets on nutrition-specific programs, illustrating a significant resource gap compared to the additional $\sim 5$ billion USD needed annually to achieve the WHA stunting targets [20].

Besides access to health care, a key determinant of stunting is the children's complementary diet [21]. The complementary feeding period (6-23 months) coincides with the timing of growth faltering, as suboptimal complementary feeding, both in quantity and quality, do not fulfill the high energy and nutrient required to sustain the rapid growth and development expected in this period [21,22]. Although poor complementary diets were observed for children from all segments of the population, the rural and the poorest wealth quintiles were again the most affected. The poor complementary feeding practices can be associated with poor nutritional-literacy, but can also reflect constraints in the availability, accessibility, and affordability of nutrient-dense foods [23-25].

Ensuring adequate supply of food, both in quantity and quality, is critical to improving diets. Although agricultural production has substantially increased in many African countries, agricultural policies have focused on cereal yields, leading to supply deficits of nutrient-dense foods, which are partly reflected in the prices of such foods [26]. For example in Ethiopia, prices of nutrient-dense foods (e.g., fruits) increased faster than the national inflation rate in the last decade [27]. Headey and Alderman [28] also show how relative prices of animal source foods, which are critical for preventing stunting [29], are much more expensive in Africa than elsewhere. Addressing socio-economic disparities in complementary feeding would thus require not only increasing coverage of nutrition education, but also calls for food systems innovations that can make nutrient-dense foods accessible and affordable for all. Aligning health and food systems is thus needed to create the much-needed synergy to increase both demand and supply of healthy diets.

\section{Strength and Limitations}

The use of the largest available, nationally representative, and mutually comparable cross-sectional DHS and MICS surveys is a key strength of this study. The disaggregation of stunting, health coverage, and complementary diets by socio-economic indicators such as wealth quintile and rural/urban residence helped unmask the disparities that would otherwise be hidden in aggregate, national-level estimates. However, the following limitations need to be considered when interpreting our findings. Two or more rounds of data were not available for all the countries and thus we were only able to provide trends for a limited number of countries. In addition, the cross-sectional nature of the study does not allow any causal inferences to be made. The CCI is composed of interventions that may not be directly related to nutrition outcomes but were used as a proxy of health care access. Because of the complex and multifactorial causes of stunting, this study is ill-equipped to explain observed disparities between countries. This calls for future studies that systematically investigate observed disparities in selected countries, possibly through regression decomposition approaches. 


\section{Conclusions}

Despite decreases in the prevalence of stunting over the past decade, the reductions in stunting were uneven between and within the countries. Stunting disproportionately affected the rural and the poorest wealth quintile. These inequalities are also observed in access to health care and the quality of complementary foods, suggesting that regional and national level estimates, although useful for monitoring and tracking progress, mask disparities by socio-economic status. Therefore, monitoring progress by socioeconomic status is critical to inform the design and implementation of interventions aiming to prevent stunting. Adequate and predictable funding for nutrition interventions, but also aligning food- and health-systems' interventions are needed to accelerate stunting reduction. Given the long-term adverse effects of stunting, attention to equity in stunting prevention efforts is critical to prevent the widening of inequalities between and within countries.

Supplementary Materials: The following are available online at http://www.mdpi.com/2072-6643/12/1/253/s1, File S1: Estimates of minimum dietary diversity, minimum meal frequency, and minimum adequate diet for children 6-23 months of age.

Author Contributions: K.B. designed the study, analyzed the data, and wrote the first draft. A.L. contributed to the analyses and the writing of the manuscript. S.C. critically reviewed the paper and contributed to the interpretation of the findings. All authors have read and agreed to the published version of the manuscript.

Funding: This work did not receive any funding

Conflicts of Interest: The authors declare that they have no competing interest.

\section{References}

1. De Onis, M.; Branca, F. Childhood stunting: A global perspective. Matern. Child Nutr. 2016, 12, 12-26. [CrossRef] [PubMed]

2. UNICEF-WHO-WB. Levels and Trends in Child Malnutrition: Key Findings of the 2019 Edition of the Joint Child Malnutrition Estimates; World Health Organization: Geneva, Switzerland, 2019.

3. World Health Organization. Global Nutrition Targets 2025: Stunting Policy Brief; World Health Organization: Geneva, Switzerland, 2014.

4. Dewey, K.G.; Begum, K. Long-term consequences of stunting in early life. Matern. Child Nutr. 2011, 7, 5-18. [CrossRef] [PubMed]

5. Alderman, H.; Hoddinott, J.; Kinsey, B. Long term consequences of early childhood malnutrition. Oxf. Econ. Pap. 2006, 58, 450-474. [CrossRef]

6. Baye, K. The Sustainable Development Goals cannot be achieved without improving maternal and child nutrition. J. Public Health Policy 2017, 38, 137-145. [CrossRef]

7. Galasso, E.; Wagstaff, A. The aggregate income losses from childhood stunting and the returns to a nutrition Intervention aimed at reducing stunting. Econ. Hum. Biol. 2019, 34, 225-238. [CrossRef]

8. Cusick, S.E.; Georgieff, M.K. The role of nutrition in brain development: The golden opportunity of the "first 1000 days.". J. Pediatr. 2016, 175, 16-21. [CrossRef]

9. Lokosang, L.; Osei, A.; Covic, N. The African union policy environment toward enabling action for nutrition in Africa. In Achieving a Nutrition Revolution for Africa the Road to Healthier Diets and Optimal Nutrition; Annual Trends and Outlook Report; International Food Policy Research Institute: Washington, DC, USA, 2016; pp. 5-11.

10. Picanyol, C.; Horton, S.; Chautala, A.; Connolly, H.; Fracassi, P.; François, J.; Lemma, F.; Mwamwaja, C.; Rayco-Solon, P.; Zagre, N.M. Tracking Investments in Nutrition in Africa; OPM Working Paper; Oxford Policy Management: Oxford, UK, 2015; Available online: https://www.opml.co.uk/files/Publications/corporatepublications/working-papers/wp-tracking-investments-in-nutrition-in-africa.pdf?noredirect=1 (accessed on 1 December 2019).

11. WHO. WHO Child Growth Standards: Length/height for Age, Weight-For-Age, Weight-For-Length, Weight-For-Height and Body Mass Index-For-Age, Methods and Development; World Health Organization: Geneva, Switzerland, 2006; ISBN 92-4-154693-X. 
12. Boerma, J.T.; Bryce, J.; Kinfu, Y.; Axelson, H.; Victora, C.G. Mind the gap: Equity and trends in coverage of maternal, newborn, and child health services in 54 Countdown countries. Lancet 2008, 371, 1259-1267.

13. Wehrmeister, F.C.; Restrepo-Mendez, M.-C.; Franca, G.V.; Victora, C.G.; Barros, A.J. Summary indices for monitoring universal coverage in maternal and child health care. Bull. World Health Organ. 2016, 94, 903-912. [CrossRef]

14. Barros, A.J.; Victora, C.G. Measuring coverage in $\mathrm{MNCH}$ : Determining and interpreting inequalities in coverage of maternal, newborn, and child health interventions. PLoS Med. 2013, 10, e1001390. [CrossRef]

15. World Health Organization. Global Nutrition Monitoring Framework: Operational Guidance for Tracking Progress in Meeting Targets for 2025; World Health Organization: Geneva, Switzerland, 2017.

16. Marmot, M.; Friel, S.; Bell, R.; Houweling, T.A.; Taylor, S. Commission on Social Determinants of Health Closing the gap in a generation: Health equity through action on the social determinants of health. Lancet 2008, 372, 1661-1669. [CrossRef]

17. Meyer, S. Inequality, world health, and global governance. Lancet 2019, 393, 2297. [CrossRef]

18. Perez-Escamilla, R.; Bermudez, O.; Buccini, G.S.; Kumanyika, S.; Lutter, C.K.; Monsivais, P.; Victora, C. Nutrition disparities and the global burden of malnutrition. BMJ 2018, 361, k2252. [CrossRef] [PubMed]

19. da Silva, I.C.M.; França, G.V.; Barros, A.J.; Amouzou, A.; Krasevec, J.; Victora, C.G. Socioeconomic inequalities persist despite declining stunting prevalence in low-and middle-income countries. J. Nutr. 2018, 148, $254-258$. [CrossRef] [PubMed]

20. Shekar, M.; Kakietek, J.; Dayton Eberwein, J.; Walters, D. An Investment Framework for Nutrition: Reaching the Global Targets for Stunting, Anemia, Breastfeeding, and Wasting; The World Bank: Washington, DC, USA, 2017; ISBN 1-4648-1010-9.

21. Stewart, C.P.; Iannotti, L.; Dewey, K.G.; Michaelsen, K.F.; Onyango, A.W. Contextualising complementary feeding in a broader framework for stunting prevention. Matern. Child Nutr. 2013, 9, 27-45. [CrossRef] [PubMed]

22. Victora, C.G.; de Onis, M.; Hallal, P.C.; Blössner, M.; Shrimpton, R. Worldwide timing of growth faltering: Revisiting implications for interventions. Pediatrics 2010, 125, e473-e480. [CrossRef] [PubMed]

23. Abebe, Z.; Haki, G.D.; Baye, K. Health extension workers' knowledge and knowledge-sharing effectiveness of optimal infant and young child feeding are associated with mothers' knowledge and child stunting in Rural Ethiopia. Food Nutr. Bull. 2016, 37, 353-363. [CrossRef]

24. Ickes, S.B.; Hurst, T.E.; Flax, V.L. Maternal Literacy, Facility Birth, and Education Are Positively Associated with Better Infant and Young Child Feeding Practices and Nutritional Status among Ugandan Children. J. Nutr. 2015, 145, 2578-2586. [CrossRef]

25. Hirvonen, K.; Hoddinott, J.; Minten, B.; Stifel, D. Children's diets, nutrition knowledge, and access to markets. World Dev. 2017, 95, 303-315. [CrossRef]

26. Baye, K.; Hirvonen, K.; Dereje, M.; Remans, R. Energy and nutrient production in Ethiopia, 2011-2015: Implications to supporting healthy diets and food systems. PLoS ONE 2019, 14, e0213182. [CrossRef]

27. Bachewe, F.; Hirvonen, K.; Minten, B.; Yimer, F. The Rising Costs of Nutritious Foods in Ethiopia; IFPRI ESSP Research Note: Addis Ababa, Ethiopia, 2017; Volume 67.

28. Headey, D.D.; Alderman, H.H. The Relative Caloric Prices of Healthy and Unhealthy Foods Differ Systematically across Income Levels and Continents. J. Nutr. 2019, 149, 2020-2033. [CrossRef]

29. Shapiro, M.J.; Downs, S.M.; Swartz, H.J.; Parker, M.; Quelhas, D.; Kreis, K.; Kraemer, K.; West, K.P., Jr.; Fanzo, J. A Systematic Review Investigating the Relation Between Animal-Source Food Consumption and Stunting in Children Aged 6-60 Months in Low and Middle-Income Countries. Adv. Nutr. 2019, 10, 827-847. [CrossRef] [PubMed]

(C) 2020 by the authors. Licensee MDPI, Basel, Switzerland. This article is an open access article distributed under the terms and conditions of the Creative Commons Attribution (CC BY) license (http://creativecommons.org/licenses/by/4.0/). 